\title{
High-Performance Transparent Ultraviolet Photodetectors Based on InGaZnO Superlattice Nanowire Arrays
}

Fangzhou Li, '† You Meng, ${ }^{\dagger}$ Ruoting Dong, ${ }^{\dagger}$ SenPo Yip, ${ }^{+}, " \chi \chi$ Changyong Lan, ${ }^{\perp}$

Xiaolin Kang, ${ }^{\dagger}$ Fengyun Wang, ${ }^{*}$ Kwok Sum Chan,, , " Johnny C. Ho, ", , , *

'Department of Materials Science and Engineering, City University of Hong Kong, Kowloon, Hong Kong

"State Key Laboratory of Terahertz and Millimeter Waves, City University of Hong Kong, Kowloon, Hong Kong

${ }^{\chi}$ Centre for Functional Photonics, City University of Hong Kong, Kowloon, Hong Kong

${ }^{\perp}$ School of Optoelectronic Science and Engineering, University of Electronic Science and Technology of China, Chengdu 610054, China

\#College of Physics and State Key Laboratory of Bio-Fibers and Eco-Textiles, Qingdao University, Qingdao 266071, China.

"Department of Physics, City University of Hong Kong, Kowloon Tong, Hong Kong *Corresponding author: Johnny C. Ho (johnnyho@,cityu.edu.hk) 
(a)

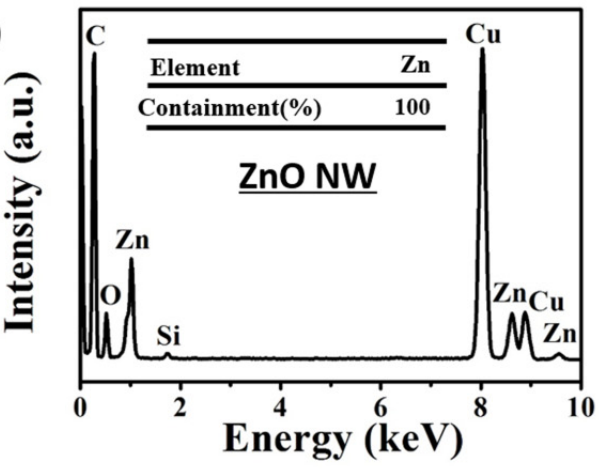

(b)

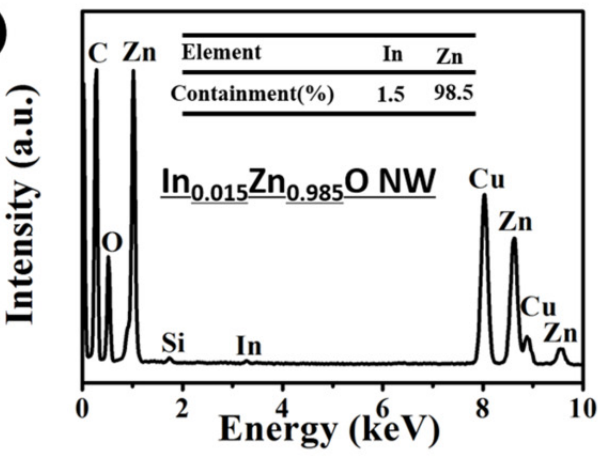

(c)

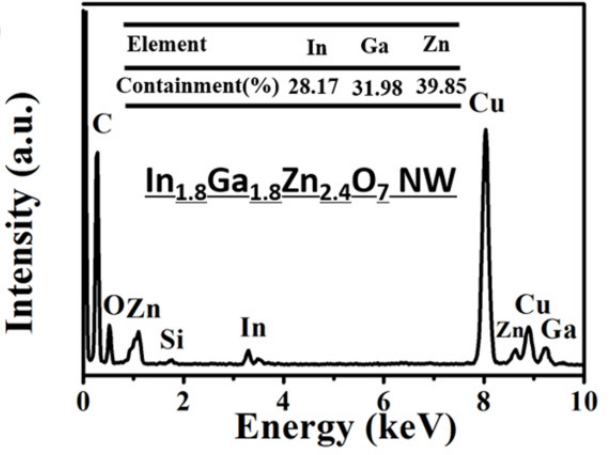

Figure S1 EDS spectra and the corresponding metallic composition of the obtained NWs after the (a) first growth run, (b) second growth run, and (c) third growth run using the same precursor source. 


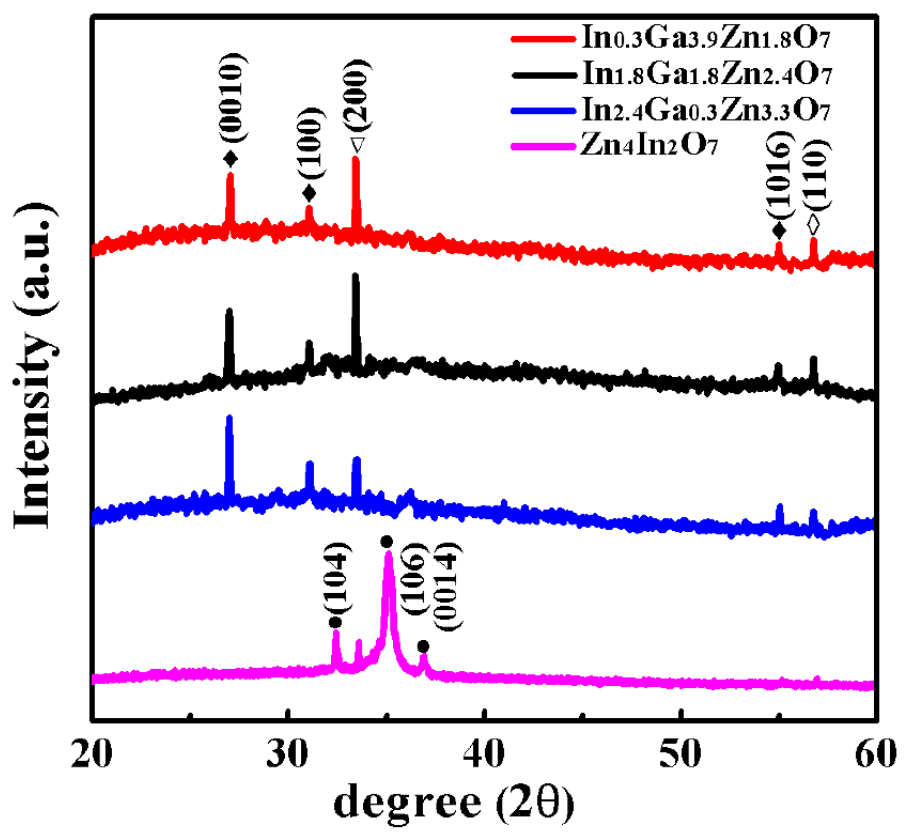

Figure S2 XRD spectra of the product, $\diamond$ : IGZO; •: IZO; $\nabla:$ Si substrate; $\diamond: \mathrm{ZnO}$. 

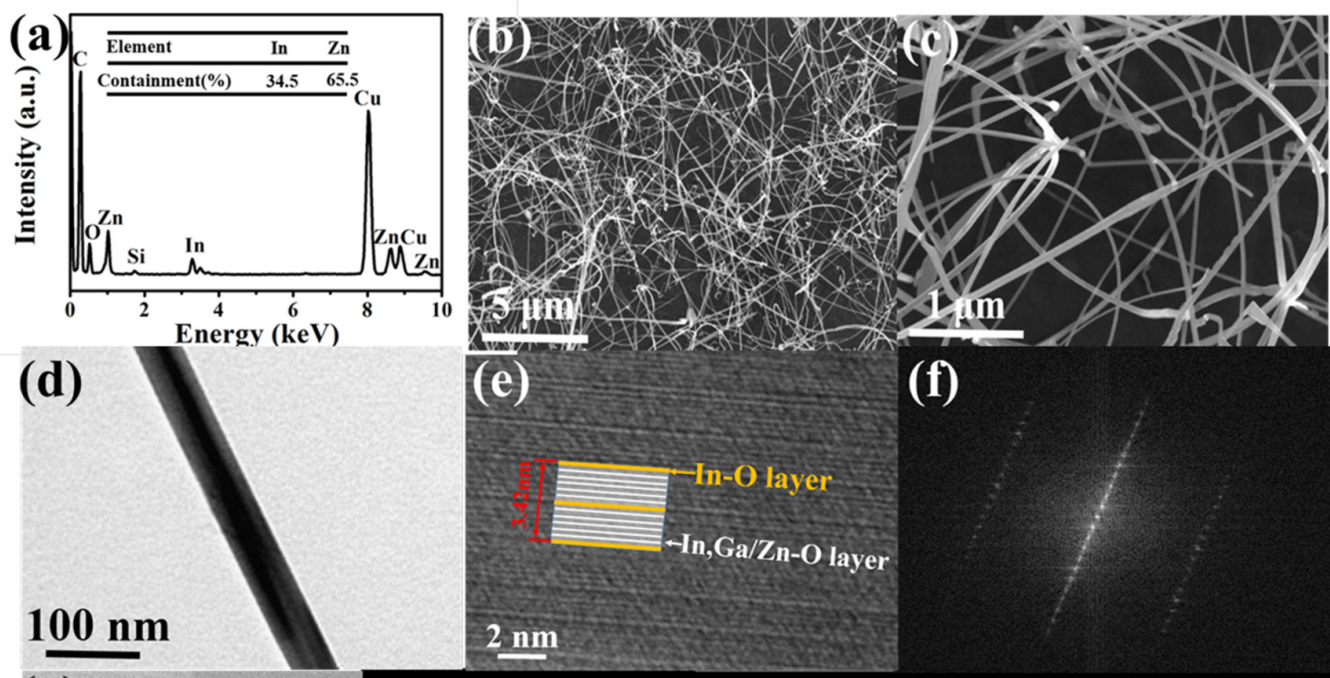

(e)

(f)

(g)

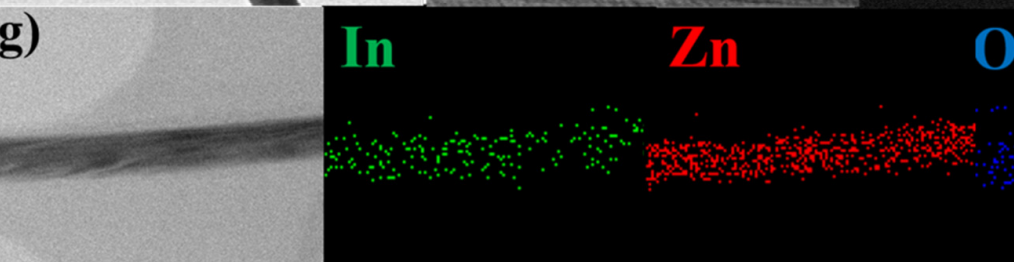

$2 \mathrm{~nm}$
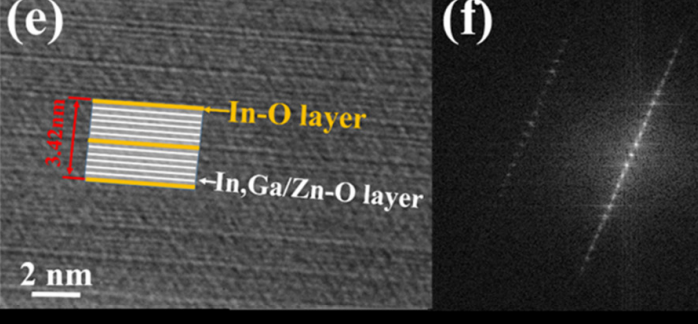

\section{$100 \mathrm{~nm}$}

Figure S3 (a) EDS, ((b), (c)) SEM, (d) TEM, ((e), (f)) HRTEM image and FFT of typical $\mathrm{Zn}_{4} \mathrm{In}_{2} \mathrm{O}_{7}$ NWs. (g) Scanning TEM image of a representative $\mathrm{Zn}_{4} \mathrm{In}_{2} \mathrm{O}_{7} \mathrm{NW}$ with the elemental mapping of $\mathrm{In}, \mathrm{Zn}$ and $\mathrm{O}$, respectively. 


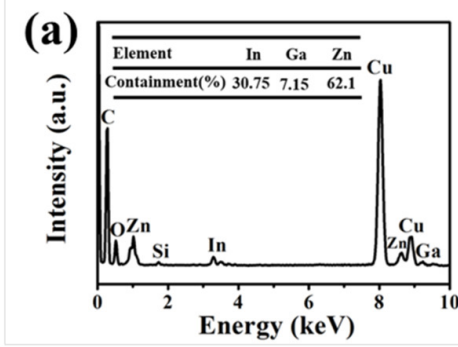

(d)

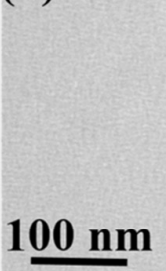

(g)
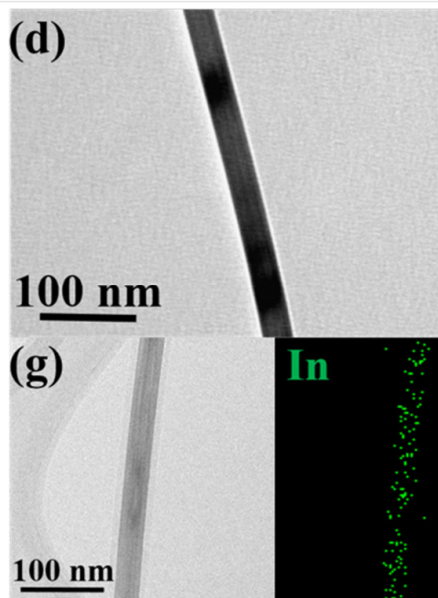

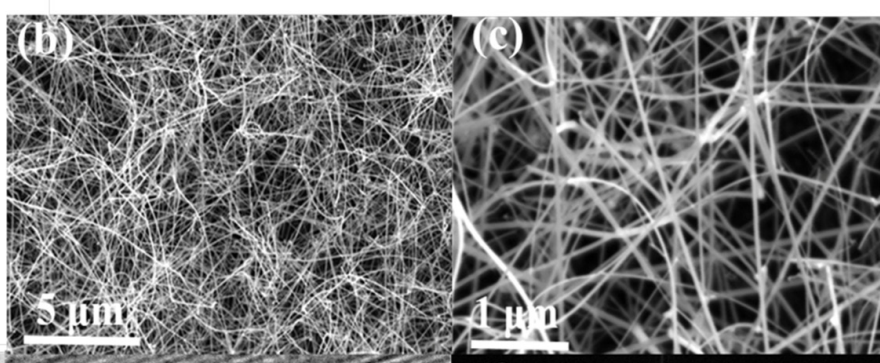

(e)

(f)

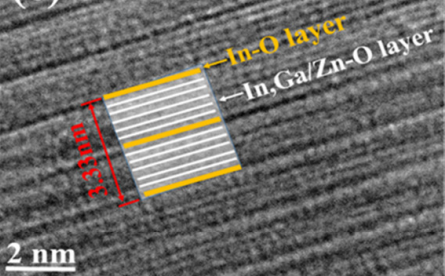

$2 \mathrm{~nm}$

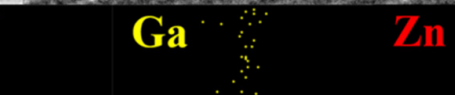

Figure S4 (a) EDS, ((b), (c)) SEM, (d) TEM, ((e), (f)) HRTEM image and FFT of typical In $2.4 \mathrm{Ga}_{0.3} \mathrm{Zn}_{3.3} \mathrm{O}_{7}$ NWs. (g) Scanning TEM image of a representative $\mathrm{In}_{2.4} \mathrm{Ga}_{0.3} \mathrm{Zn}_{3.3} \mathrm{O}_{7} \mathrm{NW}$ with the elemental mapping of $\mathrm{In}, \mathrm{Ga}, \mathrm{Zn}$ and $\mathrm{O}$, respectively. 

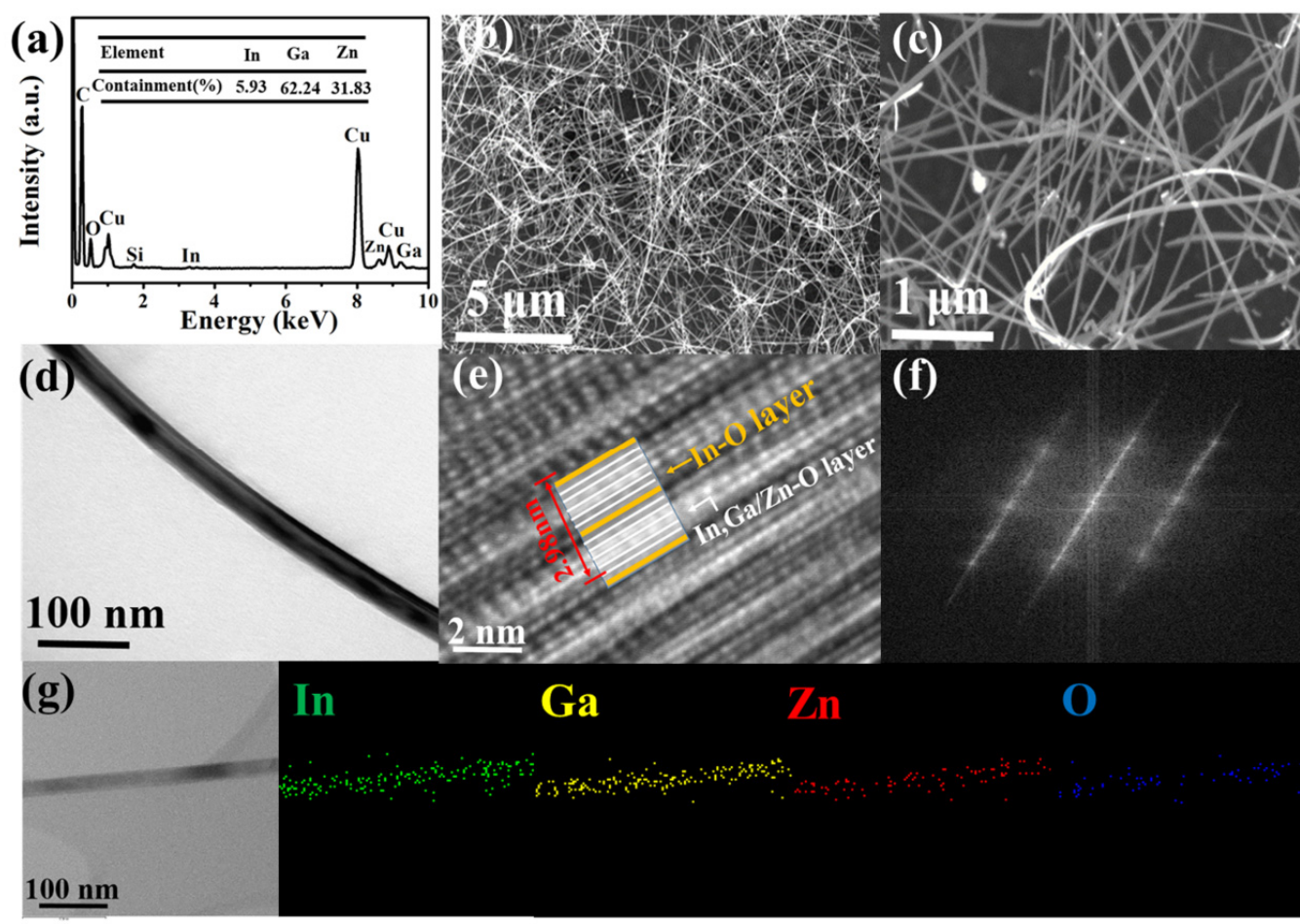

Figure S5 (a) EDS, ((b), (c)) SEM, (d) TEM, ((e), (f)) HRTEM image and FFT of typical In $0.3 \mathrm{Ga}_{.9} \mathrm{Zn}_{1.8} \mathrm{O}_{7}$ NWs. (g) Scanning TEM image of a representative $\mathrm{In}_{0.3} \mathrm{Ga}_{3.9} \mathrm{Zn}_{1.8} \mathrm{O}_{7} \mathrm{NW}$ with the elemental mapping of $\mathrm{In}, \mathrm{Ga}, \mathrm{Zn}$ and $\mathrm{O}$, respectively. 


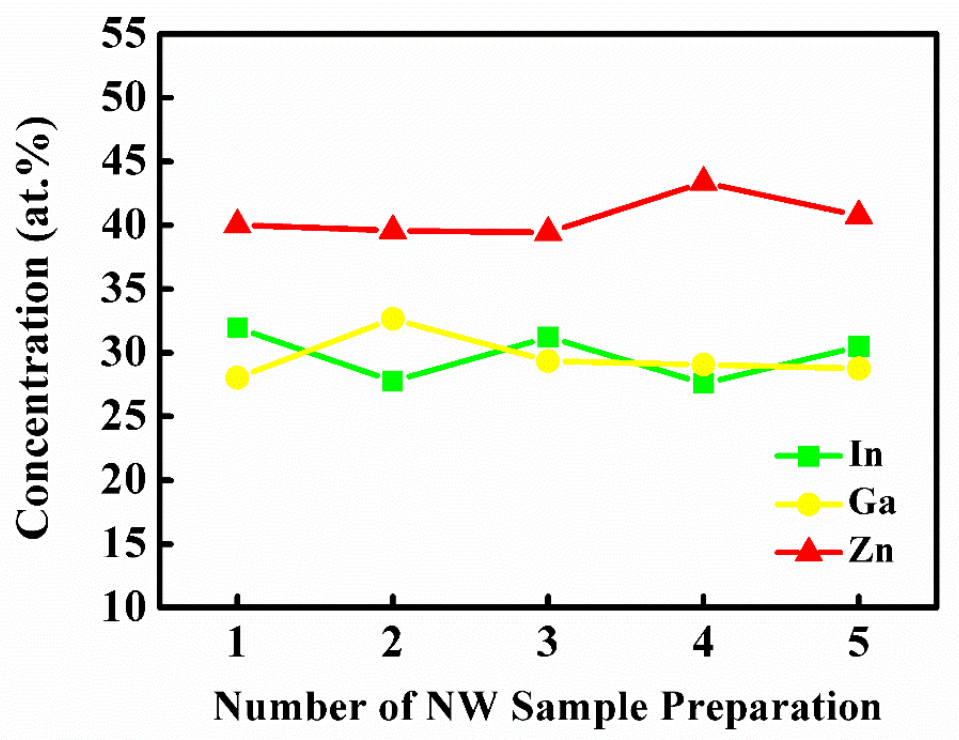

Figure S6 Variation of the concentration of metallic components of $\operatorname{In}_{1.8} \mathrm{Ga}_{1.8} \mathrm{Zn}_{2.4} \mathrm{O}_{7}$ NWs from five separate growth trials. 


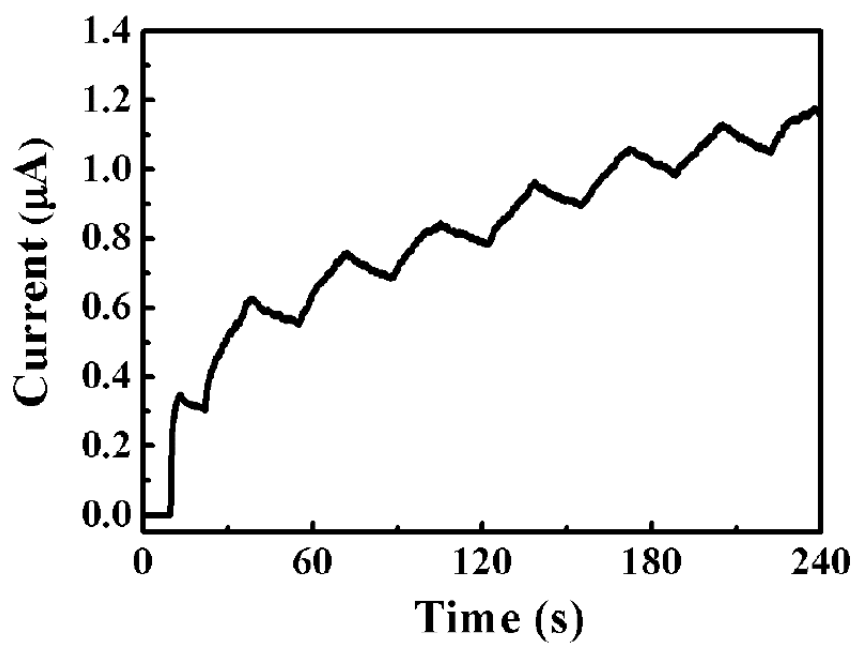

Figure S7 Current versus time curve measured under a modulated light intensity of $2.2 \mathrm{~mW} / \mathrm{cm}^{2}$ of the $\mathrm{In}_{1.8} \mathrm{Ga}_{1.8} \mathrm{Zn}_{2.4} \mathrm{O}_{7} \mathrm{NW}$ device performed under vacuum $\left(\mathrm{V}_{\mathrm{d}}=1 \mathrm{~V}\right.$ and $\left.\mathrm{V}_{\mathrm{g}}=-20 \mathrm{~V}\right)$.

In this study, the device is tested under the vacuum environment with a pressure of $3.2 \times 10^{-4} \mathrm{~Pa}$. Evidently, the current reaches $0.34 \mu \mathrm{A}$ as the UV light is turned on, but the current fails to return its original state when the light is turned off. This is totally different from the device measured in ambient under the same time scale. All these can demonstrate that the ambient gas species, especially the oxygen molecules, play a crucial role in the UV photodetection of the InGaZnO NW device. Without the oxygen gas adsorption taken place on the NW surface, the carrier depletion phenomenon cannot be existed to modulate the NW conductivity during the UV light irradiation. Notably, due to the lack of oxygen in vacuum environment, this continually increasing current during cyclic UV light irradiation is also observed in other literature reports. ${ }^{1}$ 

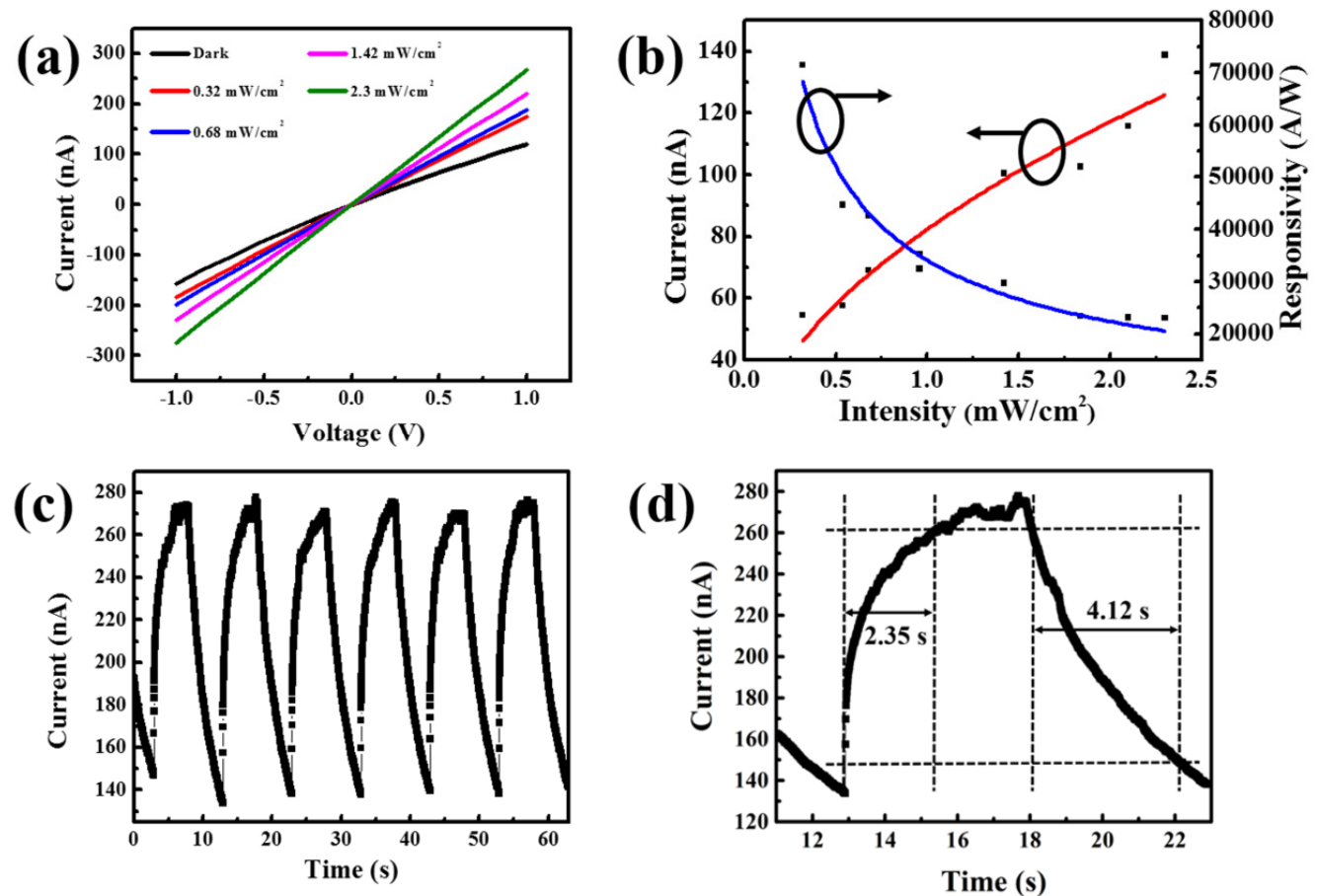

Figure S8 Photoresponse characteristics of the $\mathrm{Zn}_{4} \mathrm{In}_{2} \mathrm{O}_{7} \mathrm{NW}$ device. (a) $I-V$ results of the device under different power intensities of $261 \mathrm{~nm}$ light illumination and in the dark. (b) The dependence of the photocurrent and the responsivity on the light intensity. (c) Current versus time under the light intensity of $2.3 \mathrm{~mW} / \mathrm{cm}^{2}$. (d) A high-resolution current versus time curve. The bias is $1 \mathrm{~V}$ and $\mathrm{Vg}=-20 \mathrm{~V}$. 
(a)

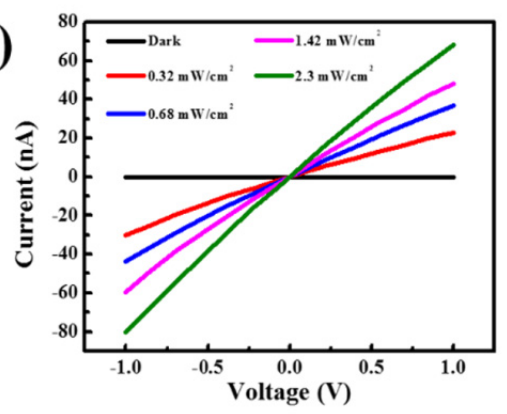

(c)

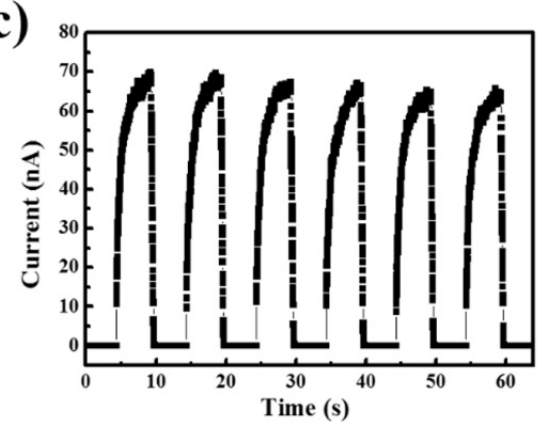

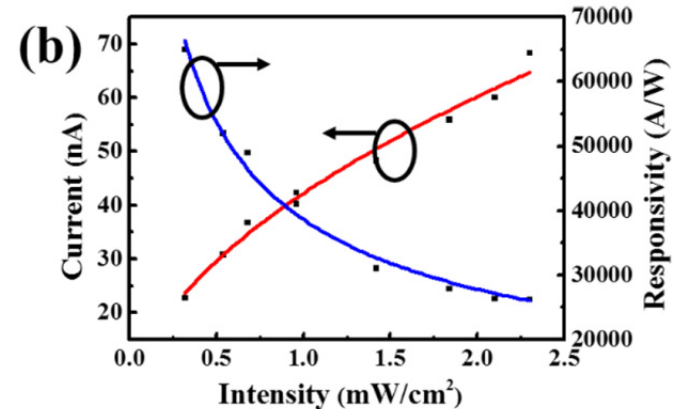

(d)

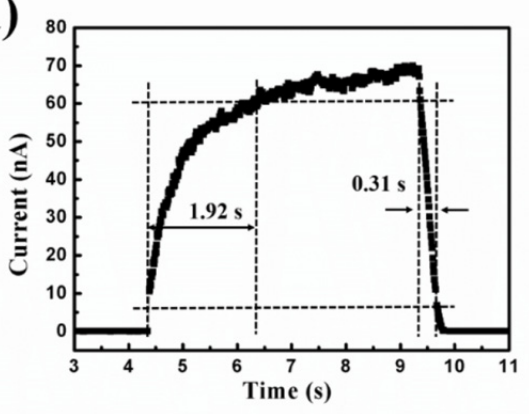

Figure S9 Photoresponse characteristics of the $\operatorname{In}_{2.4} \mathrm{Ga}_{0.3} \mathrm{Zn}_{3.3} \mathrm{O}_{7} \mathrm{NW}$ device. (a) $I-V$ results of the device under different power intensities of $261 \mathrm{~nm}$ light illumination and in the dark. (b) The dependence of the photocurrent and the responsivity on the light intensity. (c) Current versus time under the light intensity of $2.3 \mathrm{~mW} / \mathrm{cm}^{2}$. (d) A highresolution current versus time curve. The bias is $1 \mathrm{~V}$ and $\mathrm{Vg}=-20 \mathrm{~V}$. 
(a)

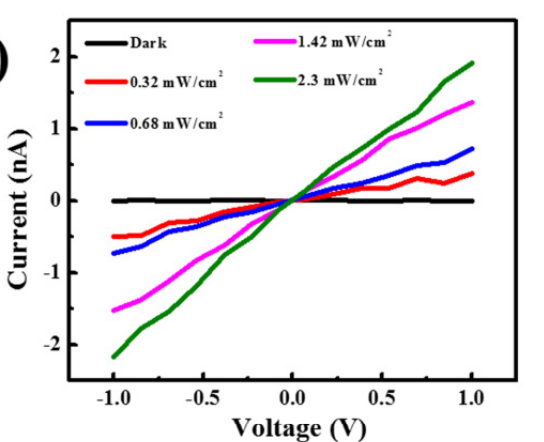

(c)

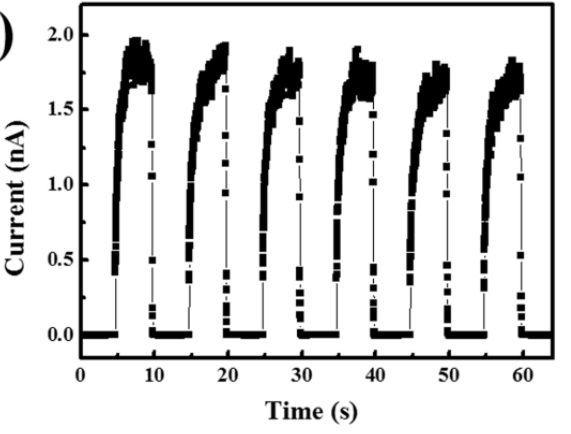

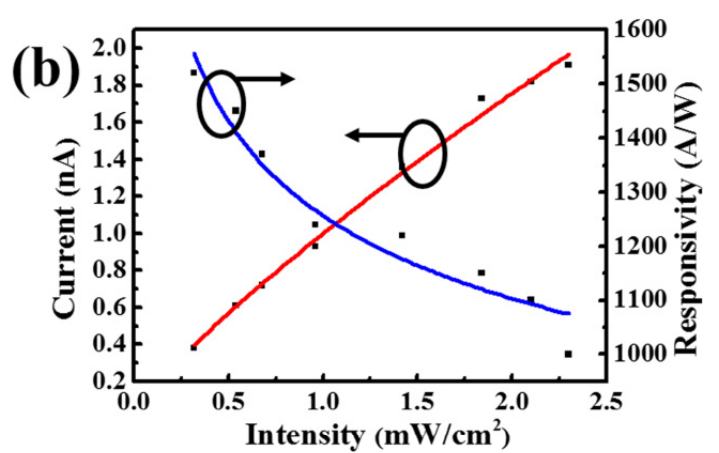

(d)

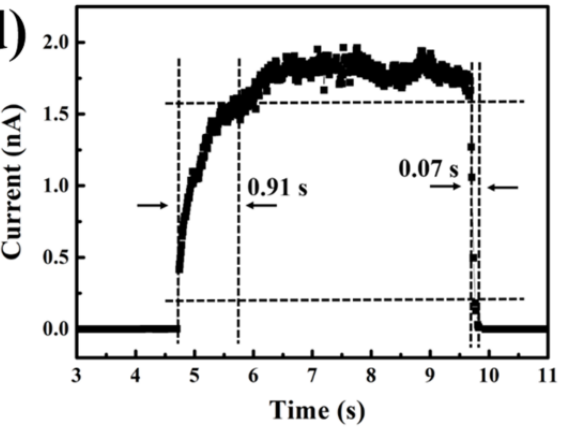

Figure S10 Photoresponse characteristics of the $\mathrm{In}_{0.3} \mathrm{Ga}_{.9} \mathrm{Zn}_{1.8} \mathrm{O}_{7} \mathrm{NW}$ device. (a) $I-V$ results of the device under different power intensities of $261 \mathrm{~nm}$ light illumination and in the dark. (b) The dependence of the photocurrent and the responsivity on the light intensity. (c) Current versus time under the light intensity of $2.3 \mathrm{~mW} / \mathrm{cm}^{2}$. (d) A highresolution current versus time curve. The bias is $1 \mathrm{~V}$ and $\mathrm{Vg}=-20 \mathrm{~V}$. 

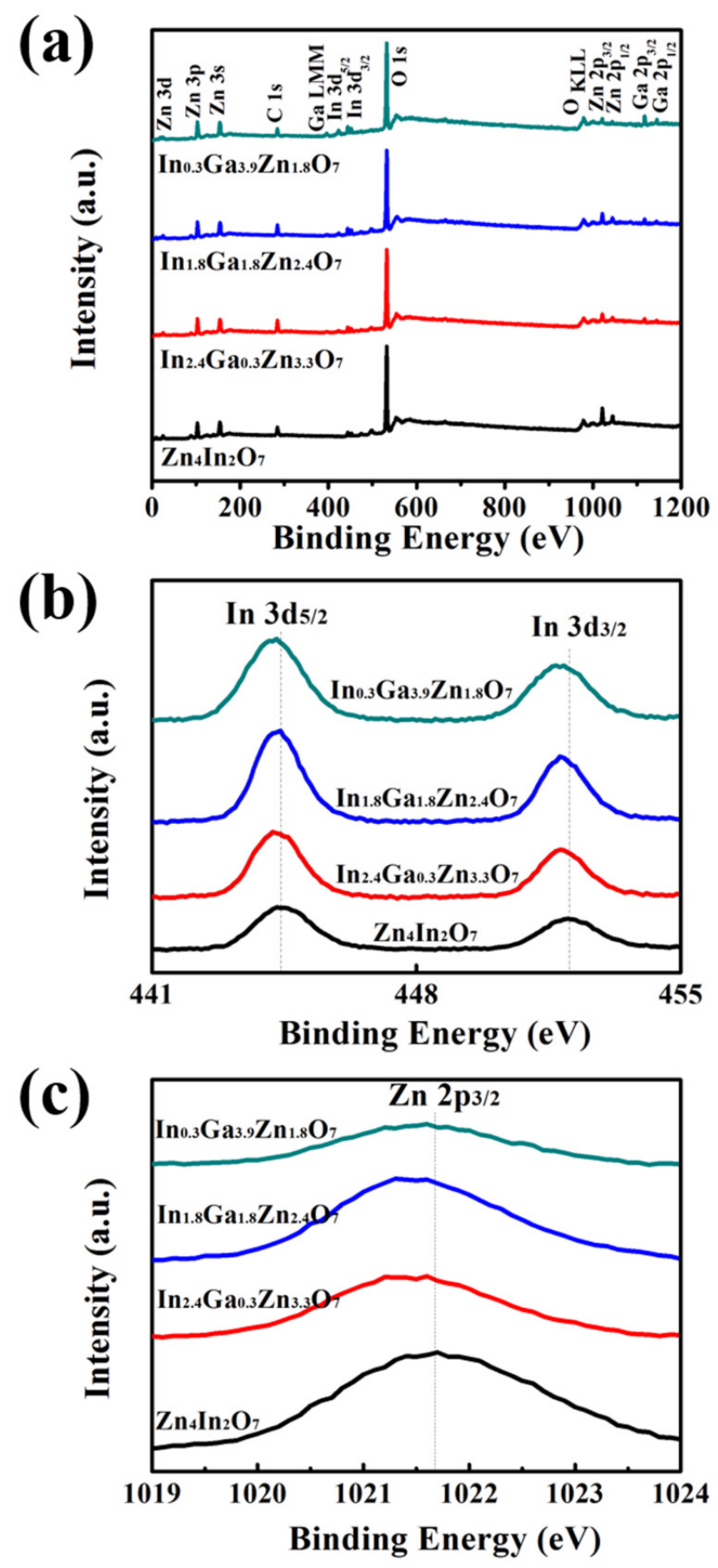

Fig S11 XPS spectra of the (a) survey spectra of $\mathrm{Zn}_{4} \operatorname{In}_{2} \mathrm{O}_{7}, \operatorname{In}_{2.4} \mathrm{Ga}_{0.3} \mathrm{Zn}_{3.3} \mathrm{O}_{7}$, $\mathrm{In}_{1.8} \mathrm{Ga}_{1.8} \mathrm{Zn}_{2.4} \mathrm{O}_{7}$ and $\mathrm{In}_{2.4} \mathrm{Ga}_{0.3} \mathrm{Zn}_{3.3} \mathrm{O}_{7}$ NWs. (b) High-resolution XPS profiles of In $3 \mathrm{~d}$ of $\mathrm{Zn}_{4} \mathrm{In}_{2} \mathrm{O}_{7}, \mathrm{In}_{2.4} \mathrm{Ga}_{0.3} \mathrm{Zn}_{3.3} \mathrm{O}_{7}, \mathrm{In}_{1.8} \mathrm{Ga}_{1.8} \mathrm{Zn}_{2.4} \mathrm{O}_{7}$ and $\operatorname{In}_{2.4} \mathrm{Ga}_{0.3} \mathrm{Zn}_{3.3} \mathrm{O}_{7} \mathrm{NWs}$, (c) $\mathrm{Zn} 2 \mathrm{p}_{3 / 2}$ of $\mathrm{Zn}_{4} \mathrm{In}_{2} \mathrm{O}_{7}, \mathrm{In}_{2.4} \mathrm{Ga}_{0.3} \mathrm{Zn}_{3.3} \mathrm{O}_{7}, \operatorname{In}_{1.8} \mathrm{Ga}_{1.8} \mathrm{Zn}_{2.4} \mathrm{O}_{7}$ and $\operatorname{In}_{2.4} \mathrm{Ga}_{0.3} \mathrm{Zn}_{3.3} \mathrm{O}_{7} \mathrm{NWs}$. 


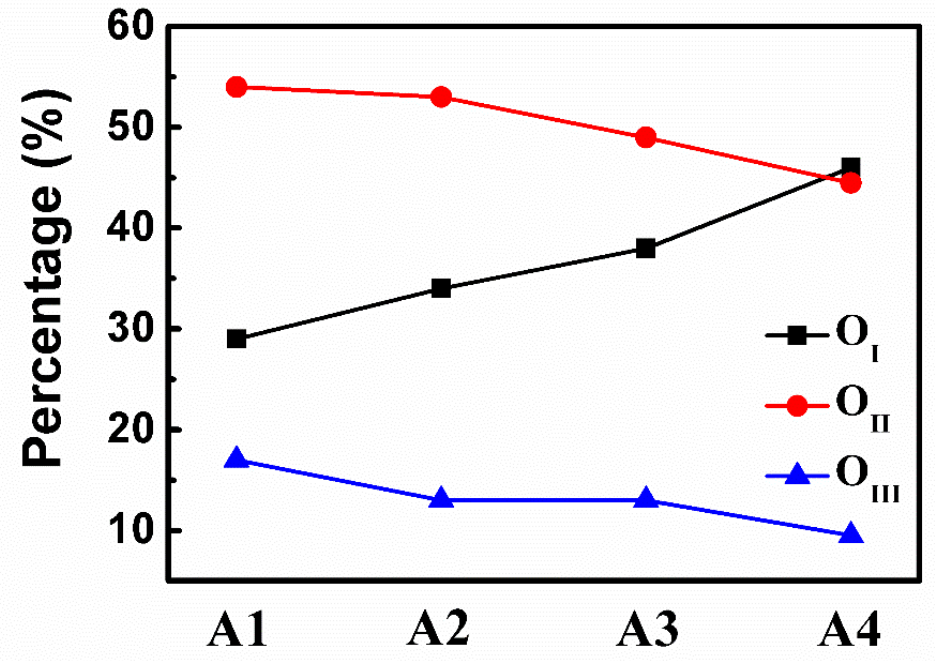

Figure S12 The variation of the peak area ratio (i.e. percentage) of OI, OII and OIII peaks of all InGaZnO NW samples. (A1: $\mathrm{Zn}_{4} \operatorname{In}_{2} \mathrm{O}_{7} ; \quad \mathrm{A} 2: \quad \operatorname{In}_{2.4} \mathrm{Ga}_{0.3} \mathrm{Zn}_{3.3} \mathrm{O}_{7} ; \quad \mathrm{A} 3$ : $\mathrm{In}_{1.8} \mathrm{Ga}_{1.8} \mathrm{Zn}_{2.4} \mathrm{O}_{7} ; \mathrm{A} 4: \mathrm{In}_{0.3} \mathrm{Ga}_{3.9} \mathrm{Zn}_{1.8} \mathrm{O}_{7 .}$ ) 
(a)

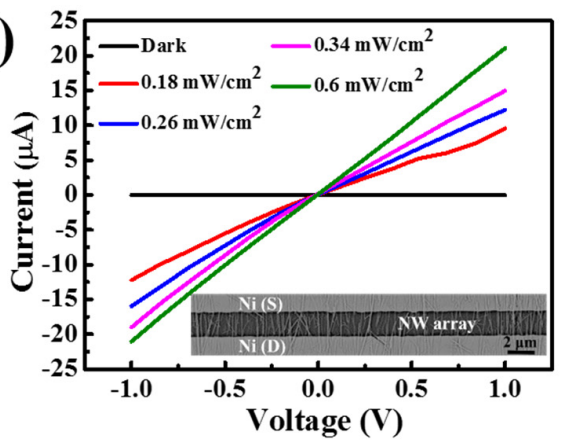

(c)

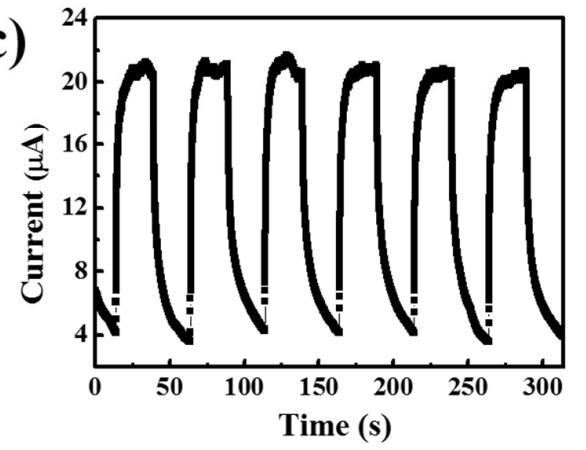

(b)

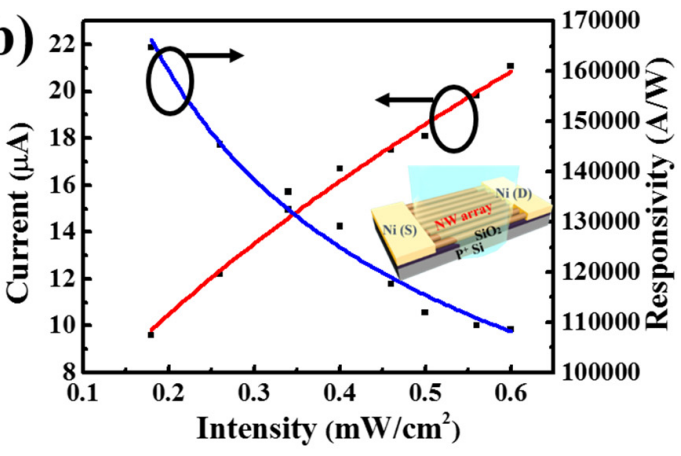

(d)

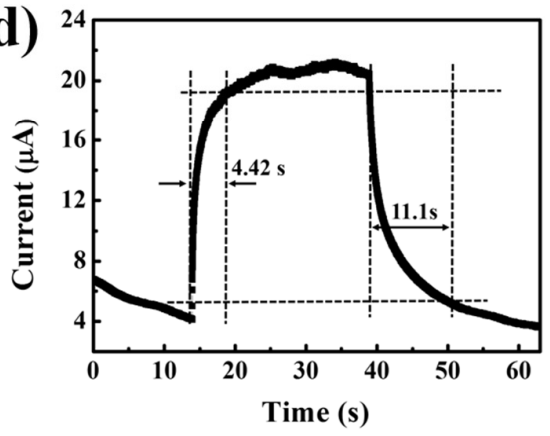

Figure S13 Photoresponse characteristics of the $\operatorname{In}_{1.8} \mathrm{Ga}_{1.8} \mathrm{Zn}_{2.4} \mathrm{O}_{7} \mathrm{NW}$ parallel arrayed device fabricated on $\mathrm{SiO}_{2} / \mathrm{Si}$ substrates. (a) $\mathrm{I}-\mathrm{V}$ results of the device under different power intensities of $261 \mathrm{~nm}$ light illumination and in the dark. The inset shows the topview SEM image of the NW parallel arrayed device channel. (b)The dependence of the photocurrent and the responsivity on the light intensity. The inset gives the device schematic of the photodetector. (c) Current versus time under the light intensity of 0.6 $\mathrm{mW} / \mathrm{cm}^{2}$. (d) A high-resolution current versus time curve. The bias is $1 \mathrm{~V}$ and $\mathrm{Vg}=-$ $20 \mathrm{~V}$.

\section{Reference:}

1. Zheng, Z.; Gan, L.; Li, H.; Ma, Y.; Bando, Y.; Golberg, D.; Zhai, T., A Fully Transparent and Flexible Ultraviolet-Visible Photodetector Based on Controlled Electrospun ZnO-CdO Heterojunction Nanofiber Arrays. Adv. Funct. Mater. 2015, 25, 5885-5894. 